\title{
Heat transfer and thermal efficiency of solar air heater having artificial roughness: a review
}

\author{
Suman Saurav ${ }^{1, *}$, M. M. Sahu ${ }^{2}$ \\ ${ }^{1}$ M. E Scholar, Lakshmi Narain College of Technology, Bhopal, Madhya Pradesh- 462041 (India) \\ ${ }^{2}$ Mechanical Engg. Deptt., Lakshmi Narain College of Technology, Bhopal, Madhya Pradesh- 462041 (India) \\ Email address: \\ sumanniist03@gmail.com (Suman Saurav),mmsahu.111@rediffmail.com (M. M. Sahu)
}

\section{To cite this article:}

Suman Saurav, M. M. Sahu. Heat Transfer and Thermal Efficiency of Solar Air Heater Having Artificial Roughness: A Review. International Journal of Renewable and Sustainable Energy. Vol. 2, No. 3, 2013, pp. 99-109. doi: 10.11648/j.ijrse.20130203.14

\begin{abstract}
Artificial roughness applied on the absorber plate is the most efficient method to improve thermal performance of solar air heaters .Experimental investigations appropriate to distinct roughness geometries shows that the enhancement in heat transfer is accompanied by considerable rise in pumping power. In view of the fact, a designer needs to carefully examine shape and orientation of roughness elements in order to choose the best fit roughness geometry for intended application. In this paper some distinguished roughness geometry has been compared on the basis of heat transfer enhancement and thermo hydraulic performance. The objective of this paper is to review various studies, in which different artificial roughness elements are used to enhance the heat transfer rate with little penalty of friction. Correlations developed by various researchers with the help of experimental results for heat transfer and friction factor for solar air heater ducts by taking different roughened surfaces geometries are given in tabular form. These correlations are used to predict the thermo hydraulic performance of solar air heaters having roughened ducts.
\end{abstract}

Keywords: Artificial Roughness, Solar Air Heater, Roughness Geometry, Nusselt Number, Friction Factor, Thermo Hydraulic Performance, Reynolds Number

\section{Introduction}

Energy plays key role for economic and social development. Demand for energy has been rising rapidly with growing population, transportation and industrialization. Due to continuous use of fossil fuels, not only the energy starvation is felt at global level but another serious problem of environment degradation has also been resulted. The rapid depletion of conventional energy sources has necessitated search for alternative energy sources to meet the energy demand of immediate future and for generations to come. Of the many alternatives, solar energy stands out as the brightest long range promise towards meeting the continually increasing demand for energy. Solar energy is available freely, omnipresent and an indigenous source of energy provides a clean and pollution free atmosphere. The simplest and the most efficient way to utilize solar energy is to convert it into thermal energy for heating applications by using solar collectors. Solar air heaters, because of their inherent simplicity are cheap and most widely used collector devices. Solar air heaters are being used for many applications at low and moderate temperatures. Some of these are crop drying, timber seasoning, space heating, cooking etc. The thermal efficiency of solar air heater has been found to be low due low thermal capacity of air and because of low convective heat transfer coefficient between absorber plate and flowing air in the duct. Attempts has been made to enhance the heat transfer rate by use of extending surface in form of fins but the heat transfer is accompanied by pressure drop penalty. In another approach use of artificial roughness is the most effective and economic way for improving performance of solar air heater. In this approach turbulence is created by roughened surface in viscous sub layer to obtain heat transfer enhancement. Several roughness geometry has been tested so far to enhance heat transfer with consumption of pumping power. This paper is divided in to six sections which are further divided into various subsections. Section 1 gives the introduction of solar air heaters and different heat transfer enhancement techniques. Section 2 deals with the concept of artificial roughness and a brief discussion of various roughness parameters. Section 3 deals with energy balance and efficiency of a 
conventional solar air heater and the comparison among various geometries. Section 4 deals with correlations developed by various researchers and finally the paper is concluded in Section 5 and it's scope for future work is given in section 6 .

\section{Concept of Artificial Roughness}

Artificial roughness is basically a transfer enhancement technique by which thermo hydraulic performance of a solar air heater can be improved. The thermal efficiency of solar air heater is generally poor due to low heat transfer co-efficient between the absorber plate and the air flowing in to the duct due to the formation of laminar sub layer on the absorber plate which acts as heat transferring surface. So there is a need to break the laminar sub layer therefore, artificial roughness has been used extensively for the enhancement of forced convective heat transfer, which further requires flow at the heat-transferring surface to be turbulent. However, energy for creating such turbulence has to come from the fan or blower and the excessive power is required to flow air through the duct. Therefore, it is desirable that the turbulence must be created only in the region very close to the heat transferring surface, so that the power requirement may be reduced.

This can be done by keeping the height of the roughness element to be small in comparison to duct dimension. The basic dimensionless geometrical parameters that are used to characterize roughness are:

1. Relative roughness pitch $(\mathrm{p} / \mathrm{e})$ : Relative roughness pitch $(\mathrm{p} / \mathrm{e})$ is defined as the ratio of distance between two consecutive ribs and height of the rib.

2. Relative roughness height (e/ D): Relative roughness height (e/ D) is the ratio of rib height to equivalent diameter of the air passage.

3. Angle of attack $(\alpha)$ : Angle of attack is inclination of rib with direction of air flow in duct.

4. Aspect ratio: It is ratio of duct width to duct height. This factor also plays a very crucial role in investigating thermo-hydraulic performance.

\section{Energy Balance and Efficiency of Conventional Solar Air Heater}

The thermal performance of flat plate solar air heater could be observed by considering the energy balance between solar energy absorbed by absorber plate and useful thermal energy output of the system accompanied by some losses. Definition sketch of energy balance of solar air heater is shown in fig. 1

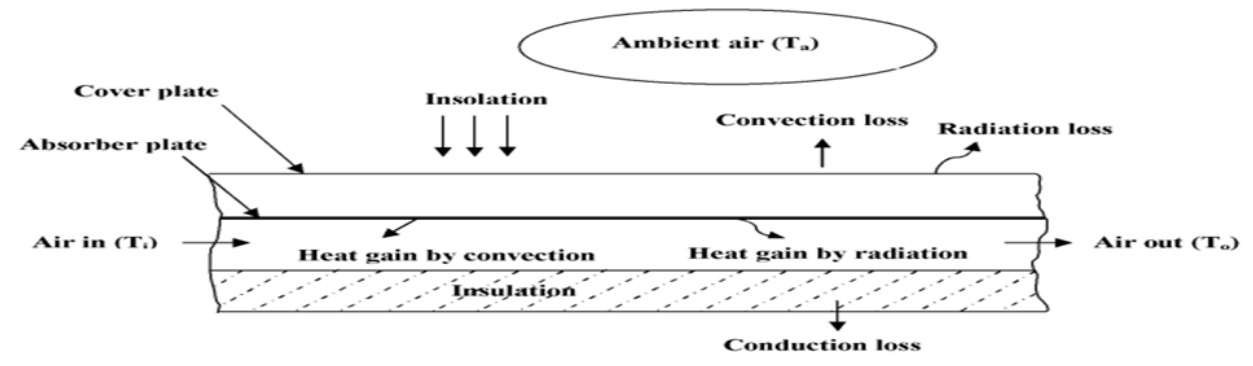

Fig 1. Definition sketch of energy balance of solar air heater

The energy balance equation can be written as follows

$$
\mathrm{Qa}=\mathrm{Ap}[\operatorname{IR}(\tau \alpha) \mathrm{e}]=\mathrm{Qu}+\mathrm{Q} 1
$$

Where Qa is the energy absorbed by the absorber plate, Ap is the area of the absorber plate, $I$ is the intensity of insolation, $\mathrm{R}$ is the conversion factor to convert radiation on horizontal surface to that on the absorber plane, $(\tau \alpha) \mathrm{e}$ is the effective transmittance absorptance product of the glass cover-absorber plate combination, $\mathrm{Qu}$ is the useful energy gain and Q1 is energy loss from the collector.

The useful energy gain can be expressed in terms of inlet air temperature $\mathrm{Ti}$ and other system and operating parameters as:

$$
\mathrm{QU}=\mathrm{AP} F R[\operatorname{IR}(\tau \alpha) \mathrm{e}-\mathrm{U} 1(\mathrm{Ti}-\mathrm{Ta})]
$$

Where FR is given by:

$$
\mathrm{FR}=\dot{m} \mathrm{cp} / \mathrm{APU} 1\left[1-\exp \left(-\mathrm{F}^{\prime} \mathrm{U} 1 \mathrm{AP} / \dot{m} \mathrm{cp}\right)\right]
$$

Where FR is the collector heat removal factor which indicates the thermal resistance meet by the absorbed solar energy in reaching to the flowing air. Ul is the overall loss coefficient and $\mathrm{Ti}$ and $\mathrm{Ta}$ are the inlet air and ambient temperatures respectively. $F^{\prime}$ is termed as collector efficiency factor which provides the relative measurement of thermal resistance between absorber plate and ambient air to that of thermal resistance between the air flowing through collector and the ambient air.

Collector efficiency factor (F') is expressed as:

$$
F^{\prime}=1 /(1+\mathrm{U} 1 / \text { he })
$$

Where he is the effective heat transfer coefficient between the absorber plate and flowing air.

The thermal efficiency of the collector is the ratio of useful heat gain to the incident solar energy falling on the collector.

Therefore: 


$$
\eta \text { th }=\mathrm{Qu} / \mathrm{IAp}=\mathrm{FR}[(\tau \alpha) \mathrm{e}-\mathrm{U} 1(\mathrm{Ti}-\mathrm{Ta}) / \mathrm{I}]
$$

According to the above equation, the thermal efficiency of the solar collector could be improved by increasing the value of FR which depends on collector efficiency factor F'. By enhancing the heat transfer coefficient between absorber plate and air, higher values of F' could be achieved. Roughening of absorber surface has been found to be the convenient and effective technique to enhance the convective heat transfer rates from the absorber surface to air.

Several experimental studies of heat transfer and friction characteristics have been carried out for solar air heater applications. In solar air heaters, one broad wall of the rectangular section air flow passage is subjected to uniform heat flux, while the remaining three walls are insulated. Therefore, the solar air heaters are modeled as a rectangular channel having one rough wall and three smooth walls.
This makes the fluid flow and heat transfer characteristics distinctly different from those found in the case of a channel with two opposite roughened walls, roughened annular and circular tubes. Various researchers have investigated the effect of different roughness parameters of artificial roughness elements in thermo-hydraulic characteristics for solar air heater. The effect of different roughness parameters on thermo hydraulic characteristics as investigated by various researchers is given below.

\subsection{Relative Roughness Pitch (p/e)}

Various investigators have shown the effect of a relative roughness pitch $(\mathrm{p} / \mathrm{e})$ on the flow pattern i.e. heat transfer coefficient and friction factor. Table 1 shows the value of relative roughness pitch $(\mathrm{p} / \mathrm{e})$ for a maximum value of a heat transfer coefficient for different types of artificial roughness.

Table 1. Relative roughness pitch (p/e) for a maximum value of a heat transfer coefficient for different types of artificial roughness.

\begin{tabular}{|c|c|c|}
\hline Investigators & Roughness Geometry & $\begin{array}{l}\text { Value of }(\mathrm{p} / \mathrm{e}) \text { for maximum heat } \\
\text { transfer coefficient }\end{array}$ \\
\hline $\begin{array}{l}\text { Abdul-Malik Ebrahim momin, J.S.Saini,S.C. Solanki } \\
\text { (2001) }\end{array}$ & $\mathrm{V}$ shaped rib roughness & 10 \\
\hline RajendraKarwa, S.C.Solanki,J.S.Saini (2000) & Integral chamfered rib & 7.9 \\
\hline $\begin{array}{l}\text { J.L.Bhagoria, J.S.Saini,S.C. } \\
\text { Solanki (2001) }\end{array}$ & Transverse wedge shape & 7.52 \\
\hline M.M.Sahu, J.L.Bhagoria (2005) & $90^{\circ}$ broken transverse rib & 20 \\
\hline A.R.Jaurker,J.S.Saini (2005) & Rib-grooved & 6 \\
\hline Varun,R.P.Saini,S.K.Singal(2007) & Combination of inclined \& transverse ribs & 8 \\
\hline K.R.Aharwal, B.K.Gandhi, J.S.Saini (2007) & Gap in inclined continuous rib & 10 \\
\hline S.V.Krmare, A.N.Tikekar (2008) & Metal rib grits roughness & 17.5 \\
\hline Apurba Layek, J.S.Saini,S.C. Solanki (2008) & Transverse chamfered rib-groove & 10 \\
\hline S.K.Saini,R.P. Saini (2008) & Arc shaped wire & 10 \\
\hline $\begin{array}{l}\text { Thakur Sanjay Kumar,Vijay Mittal, N.S. Thakur, } \\
\text { Anoop Gautum (2011) }\end{array}$ & $60^{\circ}$ inclined continuous discrete rib & 12 \\
\hline $\begin{array}{l}\text { Sachin Choudhary, Varun, Manish Kumar Chouhan } \\
\text { (2012) }\end{array}$ & Continuous M shaped ribs turbulators & 25 \\
\hline A.M.Lanjewar, J.L.Bhagoria, R.M.Sarviya (2012) & W-Shaped & 10 \\
\hline
\end{tabular}

\subsection{Relative Roughness Height (e/D)}

Various investigators have investigated the flow pattern downstream of a rib and effect on the laminar sub-layer as the rib height is changed respectively. Table 2 shows the values of the relative roughness height $(e / D)$ for a maximum value of heat transfer coefficient.

\subsection{Angle of Attack ( $\alpha$ )}

Various researchers have investigated experimentally, the effect of angle of attack on the flow pattern. This parameter that has been found to be most influential to flow pattern is the angle of inclination of the rib i.e. angle of attack of flow with respect to the rib position. The inclined rib gives a higher heat transfer rate than the transverse rib because of the secondary flow induced by the rib, in addition to breaking the viscous sub-layer and producing local wall turbulence. Table 3 shows the value of angle of attack $(\alpha)$ for a maximum value of a heat transfer coefficient for different types of artificial roughness.

\subsection{Shape of Roughness Elements}

Instead of relative roughness pitch, relative roughness height and angle of attack, shapes of various roughness elements also influence the heat transfer coefficient and friction factor. Different shapes of roughness elements are discussed as below:

\subsubsection{V-shaped Rib}

Momin,Saini,Solanki [1] investigated the effect of geometrical parameters of V-shaped ribs on heat transfer and fluid flow characteristics of rectangular duct of solar air heater with absorber plate having V-shaped ribs on its underside. The range of parameters for this study has been decided on the basis of practical considerations of the system and operating conditions. The investigation has 
covered a Reynolds number (Re) range of 2500-18000, relative roughness height $(\mathrm{e}=\mathrm{Dh})$ of $0.02-0.034$ and angle

of attack of flow $(\alpha)$ of $30^{\circ}-90^{\circ}$ for a fixed relative pitch of 10.

Table 2. Relative roughness height (e/ D) for a maximum value of heat transfer coefficient

\begin{tabular}{|c|c|c|}
\hline Investigators & Roughness Geometry & $\begin{array}{l}\text { Value of }(\mathrm{e} / \mathrm{d}) \text { for maximum heat transfer } \\
\text { coefficient }\end{array}$ \\
\hline $\begin{array}{l}\text { Abdul-MalikEbrahim momin, J.S.Saini,S.C. } \\
\text { Solanki (2001) }\end{array}$ & V shaped rib roughness & 0.034 \\
\hline RajendraKarwa, S.C.Solanki,J.S.Saini (2000) & Integral chamfered rib & 0.041 \\
\hline J.L.Bhagoria, J.S.Saini,S.C. Solanki (2001) & Transverse wedge shape & 0.033 \\
\hline M.M.Sahu, J.L.Bhagoria (2005) & $90^{\circ}$ broken tranvers rib & 0.0338 \\
\hline A.R.Jaurker,J.S.Saini (2005) & Rib-grooved & 0.0363 \\
\hline Varun,R.P.Saini,S.K.Singal(2007) & Combination of inclined \& transverse ribs & 0.030 \\
\hline K.R.Aharwal, B.K.Gandhi, J.S.Saini (2007) & Gap in inclined continuous rib & 0.0377 \\
\hline S.V.Krmare, A.N.Tikekar (2008) & Metal rib grits roughness & 0.044 \\
\hline Apurba Layek, J.S.Saini,S.C. Solanki (2008) & Transverse chamfered rib-groove & 0.03 \\
\hline S.K.Saini,R.P. Saini (2008) & Arc shaped wire & 0.0422 \\
\hline $\begin{array}{l}\text { Sanjay Kumar,Vijay Mittal, N.S. Thakur, Anoop } \\
\text { Gautum (2011) }\end{array}$ & $60^{\circ}$ inclined continuous discrete rib & 0.0498 \\
\hline $\begin{array}{l}\text { Sachin Choudhary, Varun, Manish Kumar Chouhan } \\
\text { (2012) }\end{array}$ & Continuous $\mathrm{M}$ shaped ribs turbulators & 0.0777 \\
\hline A.M.Lanjewar, J.L.Bhagoria, R.M.Sarviya (2012) & W-Shaped & 0.018 \\
\hline
\end{tabular}

Table 3. Angle of attack ( $\alpha$ ) for a maximum value of a heat transfer coefficient for different types of artificial roughness

\begin{tabular}{|c|c|c|}
\hline Investigators & Roughness Geometry & $\begin{array}{l}\text { Value of }(\alpha) \text { for maximum heat transfer } \\
\text { coefficient }\end{array}$ \\
\hline $\begin{array}{l}\text { Abdul-MalikEbrahim momin, J. S. Saini, S. C. } \\
\text { Solanki (2001) }\end{array}$ & V shaped rib roughness & $60^{\circ}$ \\
\hline J. L. Bhagoria, J. S. Saini,S. C. Solanki (2001) & Transverse wedge shape & $90^{\circ}$ \\
\hline M. M. Sahu, J. L. Bhagoria (2005) & $90^{\circ}$ broken tranverse rib & $90^{\circ}$ \\
\hline K. R. Aharwal, B. K. Gandhi, J. S. Saini (2007) & Gap in inclined continuous rib & $60^{\circ}$ \\
\hline S. V. Krmare, A. N. Tikekar (2008) & Metal rib grits roughness & $60^{\circ}$ \\
\hline Apurba Layek, J. S. Saini,S. C. Solanki (2008) & Transverse chamfered rib-groove & $60^{\circ}$ \\
\hline S. K. Saini, R. P. Saini (2008) & Arc shaped wire & $(\alpha / 90=0.3333)$ \\
\hline $\begin{array}{l}\text { Thakur Sanjay Kumar,Vijay Mittal, N. S. Thakur, } \\
\text { Anoop Gautum (2011) }\end{array}$ & $60^{\circ}$ inclined continuous discrete rib & $60^{\circ}$ \\
\hline $\begin{array}{l}\text { Sachin Choudhary, Varun, Manish Kumar } \\
\text { Chouhan (2012) }\end{array}$ & Continuous $\mathrm{M}$ shaped ribs turbulators & $60^{\circ}$ \\
\hline $\begin{array}{l}\text { A. M. Lanjewar, J. L. Bhagoria, R. M. Sarviya } \\
(2012)\end{array}$ & W-Shaped & $60^{\circ}$ \\
\hline
\end{tabular}
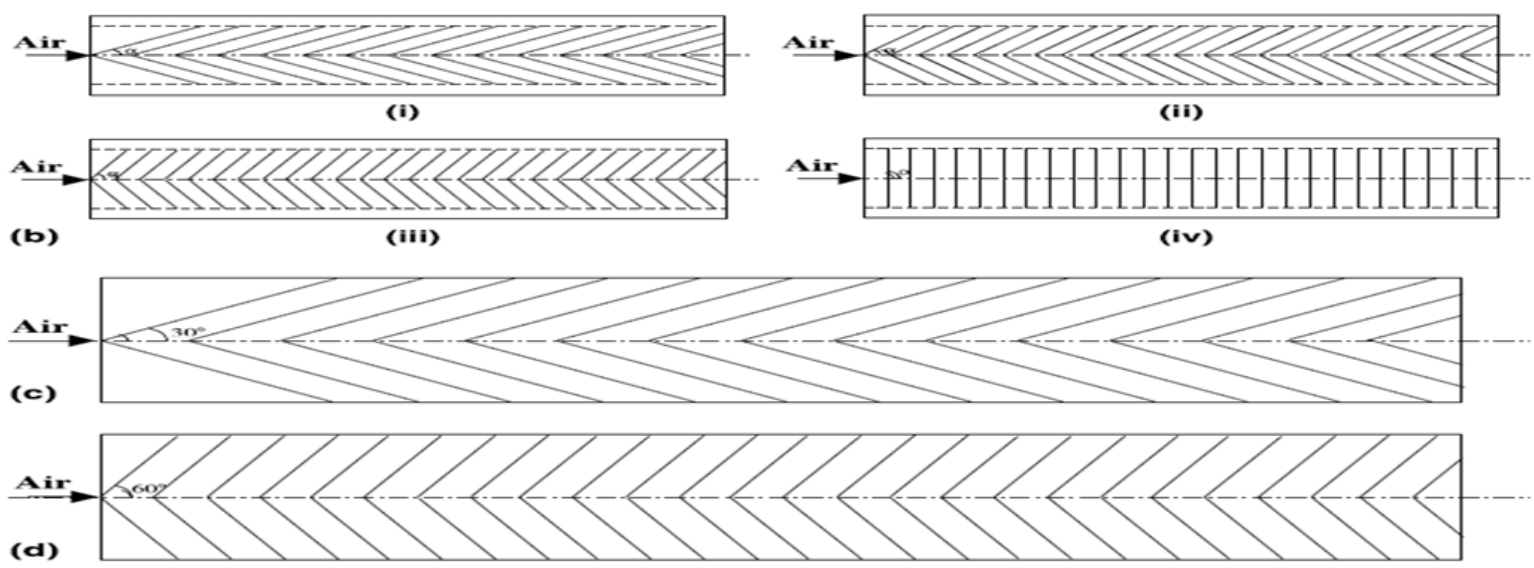

Fig 2. (a) Schematic diagram of experimental set-up. (b) Roughness elements on absorber plate. (c) Schematic diagram of $30^{\circ}$ Vshaped ribs. (d) Schematic diagram of $60^{\circ} \mathrm{V}$-shaped ribs. 
It was found that Rate of increase of Nusselt number with an increase in Reynolds number is lower than the rate of increase of friction factor. The maximum enhancement of Nusselt number and friction factor as a result of providing artificial roughness has been found to be respectively 2.30 and 2.83 times that of smooth duct for an angle of attack of $60^{\circ}$. The thermo-hydraulic performance parameter improved with increasing the angle of attack of flow and relative roughness height and the maxima occurs with an angle of attack of $60^{\circ}$. It was found that for relative roughness height of 0.034 and for angle of attack of $60^{\circ}$, the $\mathrm{V}$-shaped ribs enhance the values of Nusselt number by 1.14 and 2.30 times over inclined ribs and smooth plate case at Reynolds number of 17034 . It means that the Vshaped ribs have definite advantage over the inclined ribs for similar operating conditions.

\subsubsection{Integral Chamfered Ribs}

Karwa,Solanki,Saini[2] investigated the performance of solar air heaters with chamfered repeated rib-roughness on the airflow side of the absorber plates. The roughened elements has a relative roughness pitch of 4.58 and 7.09 while the rib chamfer angle was fixed at $15^{\circ}$. For the airflow duct depths of $21.8,21.5$ and $16 \mathrm{~mm}$, the relative roughness heights for the three roughened plates used were $0.0197,0.0256$ and 0.0441 , respectively. The airflow rate per unit area of absorber plate has been varied between 0.024 to $0.102 \mathrm{kgs} 21 \mathrm{~m} 22$ (flow Reynolds number ranges from 3750 to 16350 ).
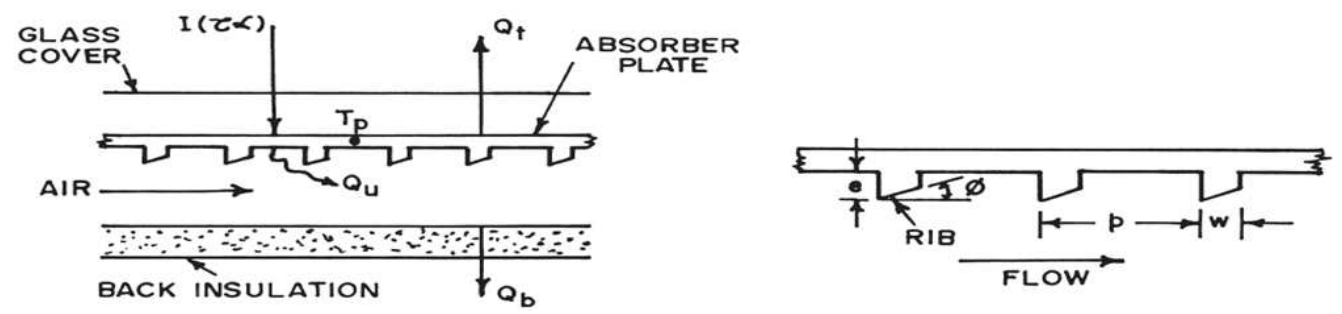

Fig 3. (a) Solar Air heater with roughened absorber plate (b) Integral chamfered rib

The study shows substantial enhancement in thermal efficiency (10 to $40 \%$ ) over solar air heaters with smooth absorber plates due to the enhancement in the Nusselt number $(50 \%$ to $120 \%)$. The thermal efficiency enhancement was also accompanied by a considerable enhancement in the pumping power requirement due to the increase in the friction factor ( $80 \%$ to $290 \%)$. The artificial roughness on the absorber plate also causes 1.8 to 3.9 times increase in the friction factor. The enhancements in the Nusselt number, friction factor and thermal efficiency were found to be strong functions of the relative roughness height. The greatest enhancement was observed for the air heater with the highest relative roughness height.

\subsubsection{Wedge Shaped Ribs}

Bhagoria, Saini, Solanki [3] performed this experiment to collect heat transfer and friction data for forced convection flow of air in solar air heater rectangular duct with one broad wall roughened by wedge shaped transverse integral ribs. The experiment encompassed the Reynolds number range from 3000 to 18000 ; relative roughness height 0.015 to 0.033 ; the relative roughness pitch $60.17 \Phi$ $1.0264<\mathrm{p} / \mathrm{e}<12.12$; and rib wedge angle (f) of $8,10,12$ and $15^{\circ}$. The effect of parameters on the heat transfer coefficient and friction factor were compared with the result of smooth duct under similar flow conditions.

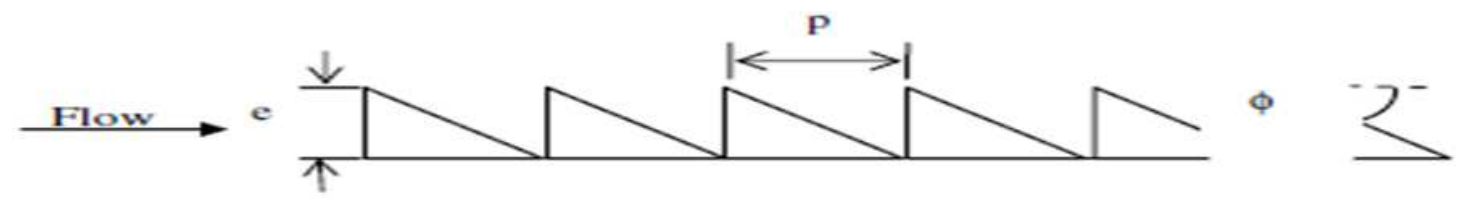

Fig 4. Orientation of wedge shaped ribs

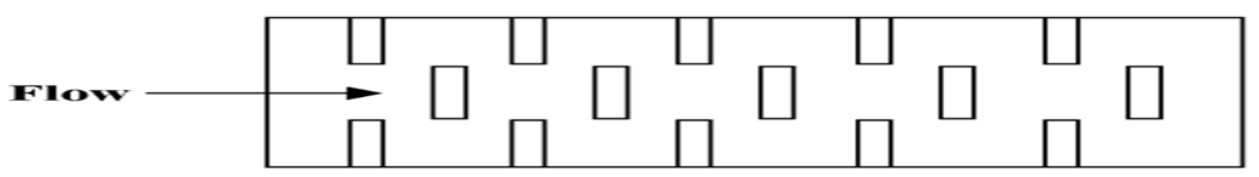

Fig 5. Broken transverse rib

They reported that as compared to the smooth duct, the presence of ribs yields Nusselt number up to 2.4 times while the friction factor rises up to 5.3 times for the range of parameters investigated. The maximum heat transfer occured for a relative roughness pitch of about 7.57 ,while the friction factor keeps decreasing as the relative roughness pitch increases and a maximum enhancement of heat transfer occurs at a wedge angle of about $10^{\circ}$ while on either side of this wedge angle, Nusselt number decreases. The friction factor increased as the wedge angle increases. 


\subsubsection{Broken Transverse Ribs}

Sahu and Bhagoria[4] carried out this experimental investigation to study the heat transfer coefficient by using $90^{\circ}$ broken transverse ribs on absorber plate of a solar air heater; the roughened wall being heated while the remaining three walls were insulated. The roughened wall has roughness with pitch $(\mathrm{P})$, ranging from $10-30 \mathrm{~mm}$, height of the rib of $1.5 \mathrm{~mm}$ and duct aspect ratio of 8 . The air flow rate corresponds to Reynolds number between $3000-12,000$. The heat transfer results has been compared with those for smooth ducts under similar flow and thermal boundary condition to determine the thermal efficiency of solar air heater.

In this investigation number it is found that the Nusselt number increases, attains a maximum for roughness pitch of $20 \mathrm{~mm}$ and decreases with an increase of roughness pitch. The value of the Nusselt number increases sharply at low Reynolds number and this becomes constant or increases very slightly in comparison to low Reynolds number. The maximum enhancement of heat transfer coefficient occurs at pitch of about $20 \mathrm{~mm}$. It was also concluded that at low Reynolds number (below 5000) a smooth duct gives better heat transfer than the artificial roughened duct. The experimental values of the thermal efficiency of the three roughened absorber plates tested have been compared with the smooth plates. A plate having roughness pitch $20 \mathrm{~mm}$ gives the highest efficiency of $83.5 \%$.

\subsubsection{Rib- Grooved Roughness}

This investigation carried out by Jaruker, Saini, Gandhi[5] encompassed the Reynolds number range from 3000 to 21,000; relative roughness height $0.0181-0.0363$; relative roughness pitch $4.5-10.0$, and groove position to pitch ratio $0.3-0.7$. This investigation clearly demonstrates that the heat transfer coefficient for rib-grooved arrangement is higher than that for the transverse ribs, whereas the friction factor is slightly higher for rib-grooved arrangement.
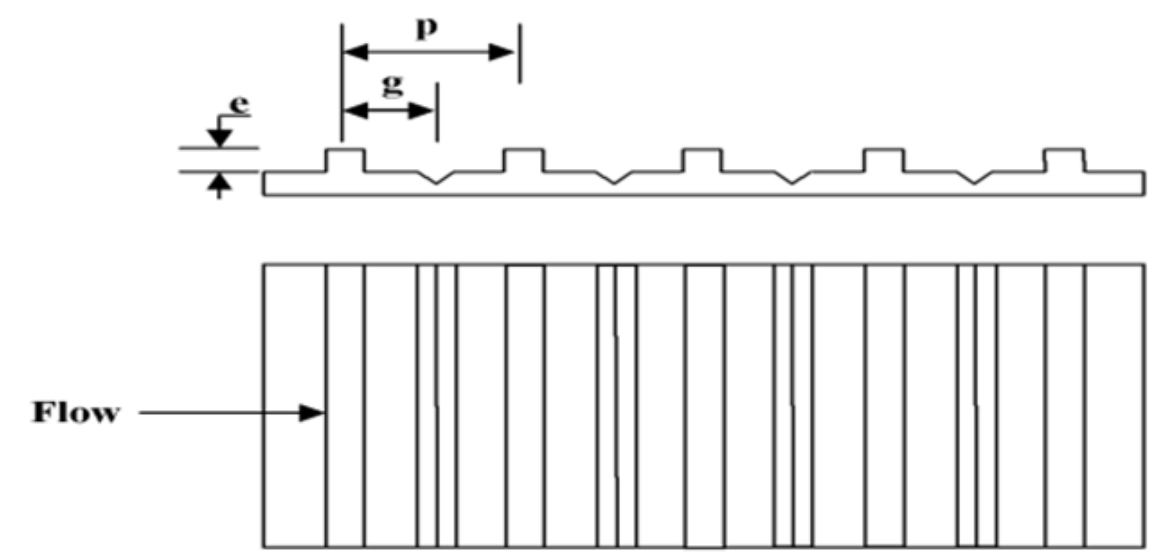

Fig 6. Rib grooved roughness

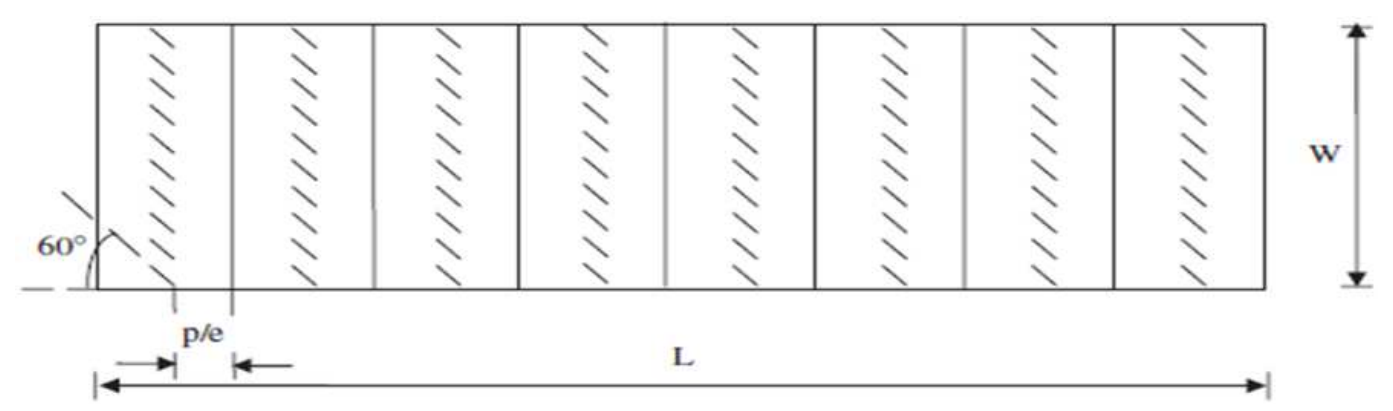

Fig 7. Combined inclined and transverse rib

In this experiment it was concluded that as compared to the smooth duct, the presence of rib grooved artificial roughness yields Nusselt number up to 2.7 times while the friction factor rises up to 3.6 times. The maximum heat transfer occurs for a relative roughness pitch of about 6.0 ,and it decreases either side of relative roughness pitch and similar trend is observed for friction factor. The optimum condition for heat transfer occurs at a groove position to pitch ratio of 0.4 , while on the either side of this ratio, both Nusselt number and friction factor decreases. It is found that the rib-grooved arrangement provides the best thermo-hydraulic performance and hence can be employed for heat transfer augmentation.

\subsubsection{Combination of Inclined and Transverse Rib}

Varun,Saini,Singal[6] carried out this experiment to study the heat transfer and friction characteristics by using a combination of inclined as well as transverse ribs on the absorber plate of a solar air heater. The experimental investigation encompassed the Reynolds number (Re) ranges from 2000 to 14000 , relative roughness pitch (p/e) 
3-8 and relative roughness height(e/Dh)0.030.

This work was undertaken with the objective of detailed investigation of roughness geometries that have a combination of transverse as well as inclined ribs. Results have been compared with those of a smooth duct under similar flow conditions to determine heat transfer coefficient and friction factor. The thermal performance of roughened solar air heater is influenced by the roughness parameters and the best performance has been found for the roughness parameter that yield maximum heat transfer coefficient. The geometry having relative roughness pitch of 8 have the maximum thermal efficiency.
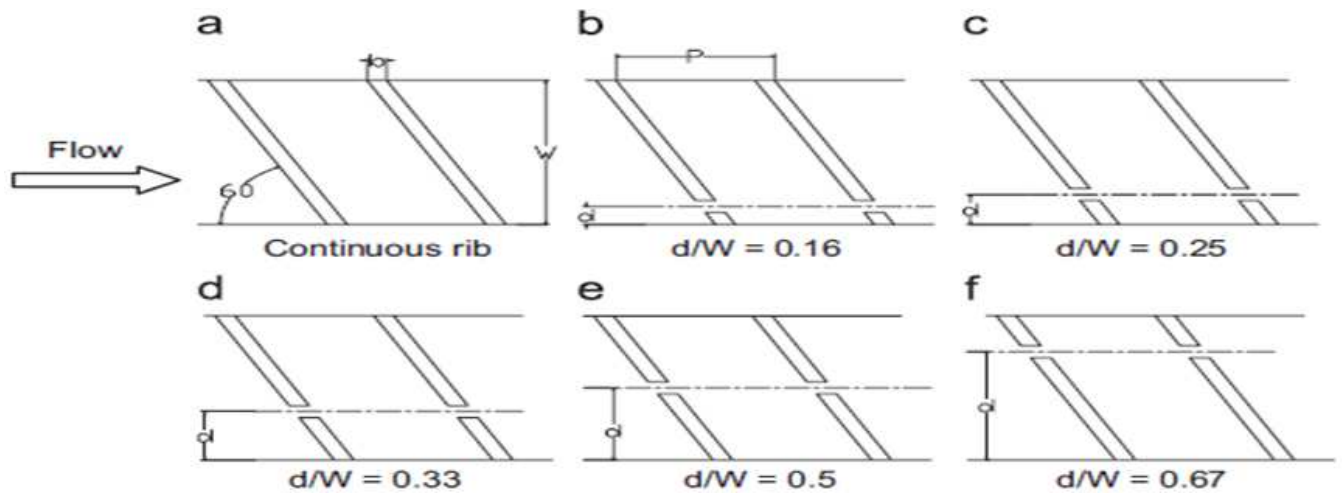

Fig 8. showing variation of gap position in an inclined rib arrangement

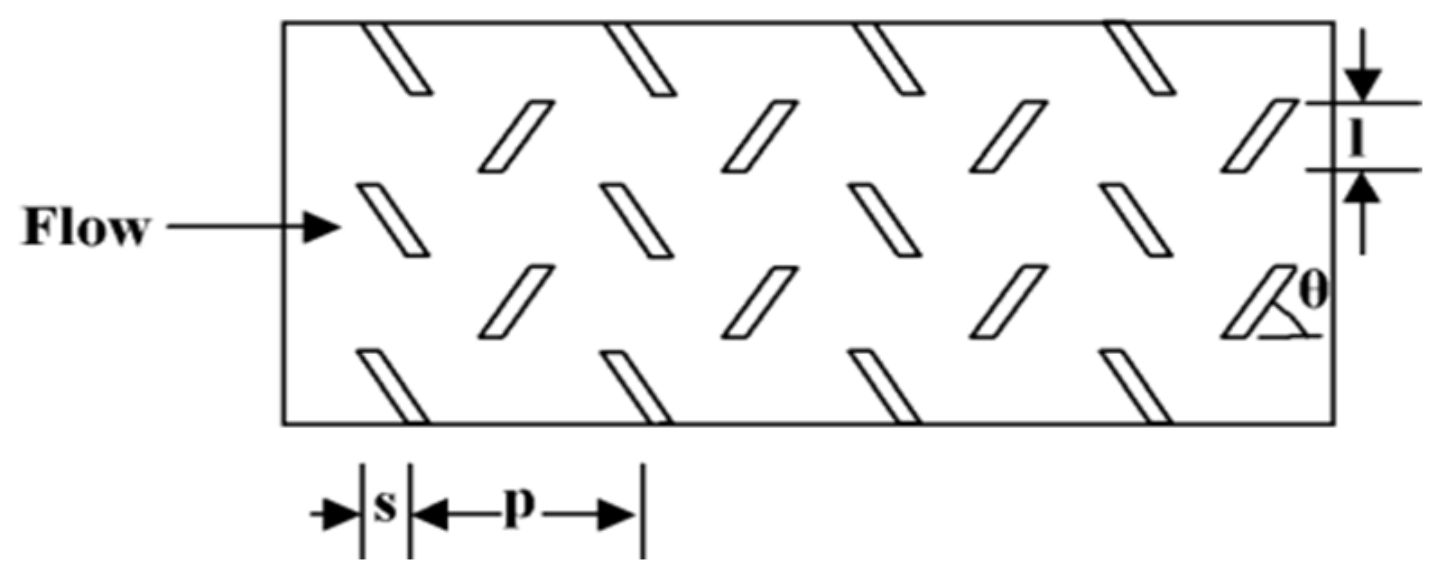

Fig 9. Metal grit ribs

\subsubsection{Gap In Inclined Continuous Rib}

Aharwal,Saini,Gandhi[7] done this experiment to to present the experimental investigation of heat transfer and friction factor characteristics of a rectangular duct roughened with repeated square cross-section split-rib with a gap, on one broad wall arranged at an inclination with respect to the flow direction. The duct has a width to height ratio $(\mathrm{W} / \mathrm{H})$ of 5.84 , relative roughness pitch $(\mathrm{P} / \mathrm{e})$ of 10 , relative roughness height $(\mathrm{e} / \mathrm{Dh})$ of 0.0377 , and angle of attack $(\alpha)$ of $60^{\circ}$. The gap width $(\mathrm{g} / \mathrm{e})$ and gap position $(d / W)$ were varied in the range of $0.5-2$ and $0.1667-0.667$, respectively. The heat transfer and friction characteristics of this roughened duct has been compared with those of the smooth duct under similar flow condition. The effect of gap position and gap width has been investigated for the range of flow Reynolds numbers from 3000 to 18,000 .

In this investigation it was found that a gap in the inclined rib arrangement enhances the heat transfer and friction factor of the roughened ducts. The increase in Nusselt number and friction factor is in the range of 1.482.59 times and 2.26-2.9 times of the smooth duct, respectively, for the range of Reynolds numbers from 3000 to 18,000 . The maximum values of Nusselt number and friction factor were observed for a gap in the inclined repeated ribs with a relative gap position of 0.25 and a relative gap width of 1.0 .

\subsubsection{Metal Rib Grit Roughness}

Karmare and Tikekar[8] investigated about thermo hydraulic performance of roughened solar air heaters with metal rib grits. The range of variation of system and operating parameters was investigated within the limits of, e/Dh: $0.035-0.044, \mathrm{p} / \mathrm{e}: 15-17.5$ and $1 / \mathrm{s}$ as 1.72 , against variation of Reynolds number, Re: $3600-17000$. The study shows substantial enhancement in thermal efficiency (10$35 \%$ ), over solar air heater with smooth collector plate.

It was discovered that Nusselt number and friction factor increases up to 2 and 3 times respectively when compared to smooth surface. Heat transfer had its maximum value at $\mathrm{e} / \mathrm{D}=0.044,1 / \mathrm{s}=1.72, \mathrm{p} / \mathrm{e}=17.5$ and friction factor had its maximum value at $\mathrm{e} / \mathrm{D}=0.044,1 / \mathrm{s}=1.72, \mathrm{p} / \mathrm{e}=12.5$. Optimum performance was found for $\mathrm{e} / \mathrm{D}=0.044, \mathrm{l} / \mathrm{s}=$ $1.72, \mathrm{p} / \mathrm{e}=17.5$. The thermal efficiency enhancement was 
also accompanied by a considerable increase in the pumping power requirement due to the increase in the friction factor $(80-250 \%)$.

\subsubsection{Transverse Chamfered Rib Groove}

Layek,Saini and Solanki[9] carried out this experiment on heat and fluid flow characteristics of fully developed turbulent flow in a rectangular duct having repeated integral transverse chamfered rib-groove roughness on one broad wall. The roughened wall is uniformly heated while the remaining three walls are insulated. These boundary conditions correspond closely to those found in solar air heaters. Six roughened plates has been tested placing a $60^{\circ}$ V-groove at the centre line in between two consecutive chamfered ribs. The ribs' top have been chamfered having chamfer angles of $5^{\circ}, 12^{\circ}, 15^{\circ}, 18^{\circ}, 22^{\circ}$ and $30^{\circ}$, while relative roughness pitch $(\mathrm{P} / \mathrm{e})$ and relative roughness height $(\mathrm{e} / \mathrm{Dh})$ of the ribs were kept constant having values of 10 and 0.03 respectively. The flow Reynolds number of the duct varied in the range of approximately 3000-21,000, most suitable for solar air heater.

They reported that as compared to smooth surface the roughened surface can yield a maximum of about 2.6-fold and 3.35-fold increase in the Nusselt number and friction factor respectively in the range of parameters investigated. The maximum enhancement of Nusselt number occurs for chamfer angle of $18^{\circ}$ but the friction factor increases monotonously with increase in chamfer angle. A substantial improvement in the thermo-hydraulic performance was obtained, as indicated by the performance parameter value lying between 1.4 and 1.76 for the range of experimentation.

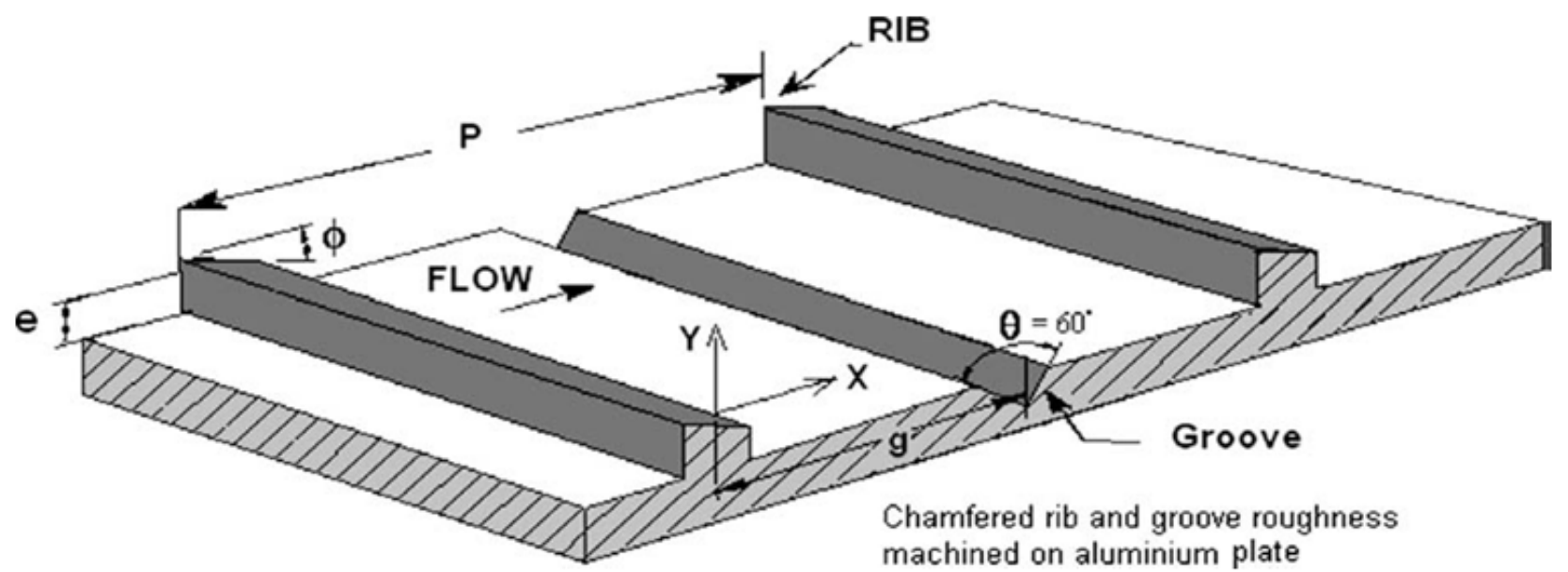

Fig 10. Showing roughness geometry

\subsubsection{Arc Shaped Roughness}

Solanki and Saini[10] carried out this experimental study for enhancement of heat transfer coefficient of a solar air heater having roughened air duct provided with artificial roughness in the form of arc-shape parallel wire as roughness element. Increment in friction factor by provided with such artificial roughness elements has also been studied. The effect of system parameters such as relative roughness height (e/d)0.0215-0.0422,(p/e)10 and arc angle $(\alpha / 90) 0.3333-0.6666$ have been studied on Nusselt number $(\mathrm{Nu})$ and friction factor (f) with Reynolds number (Re) varied from 2000 to 17000 .

It was concluded that considerable enhancement in heat transfer coefficient is achieved by providing arc-shape parallel wire geometry as artificial roughness with solar air duct. The maximum enhancement in Nusselt number has been obtained as 3.80 times corresponding the relative arc angle $(\mathrm{a} / 90)$ of 0.3333 at relative roughness height of 0.0422 . However, the increment in friction factor corresponding to these parameters has been observed 1.75 times only.

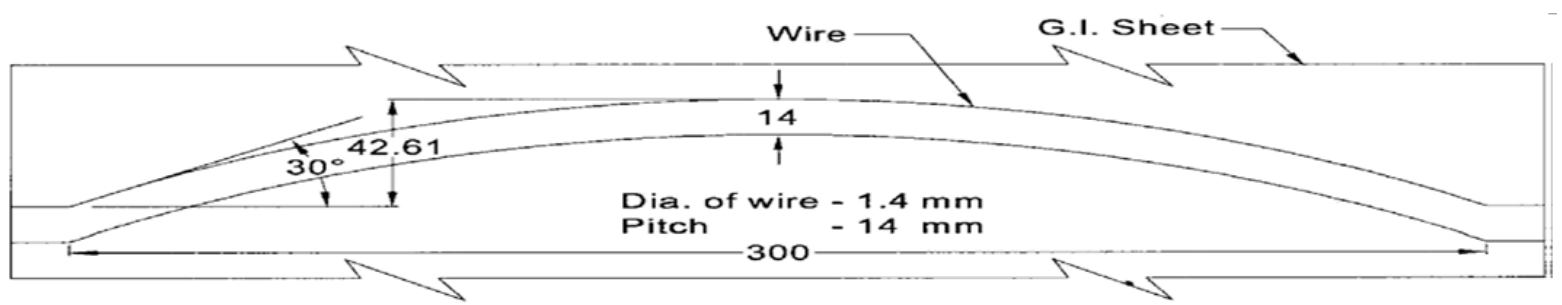

Fig 11. Arc shaped roughness 


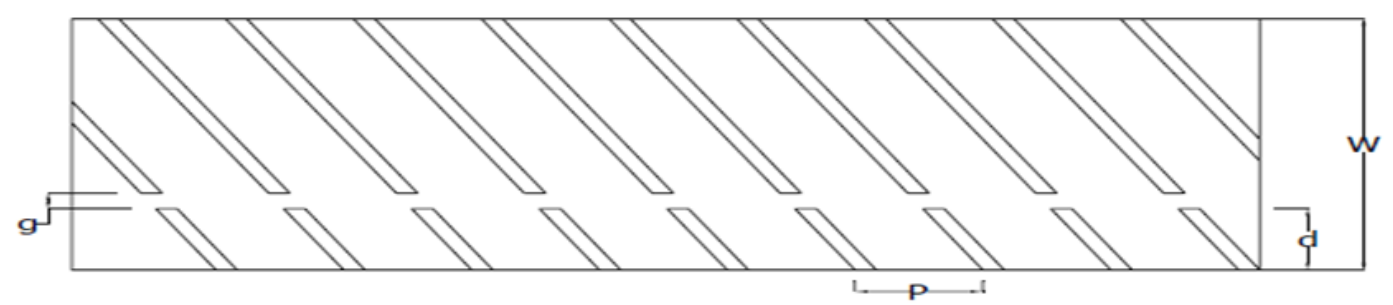

Fig 12. Geometry of $60^{\circ}$ inclined discrete rib roughness

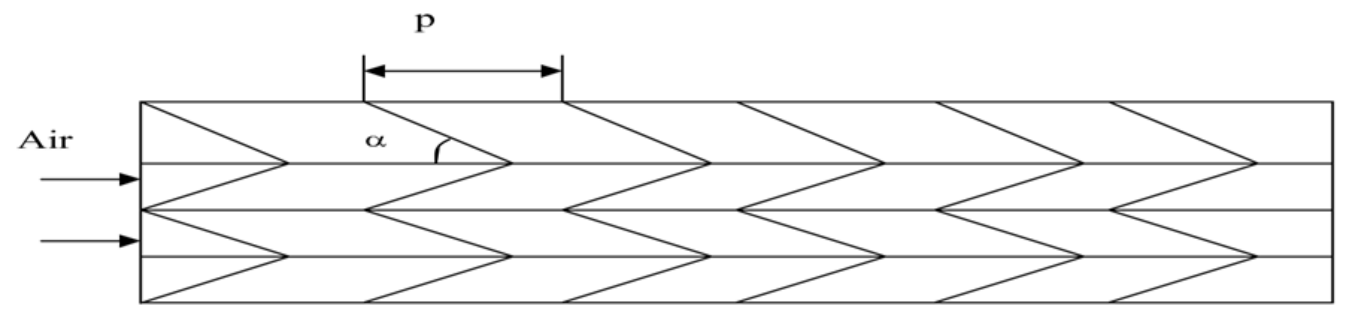

Fig 13. W-shaped roughness geometry

\subsubsection{0 ${ }^{\circ}$ Inclined Continuous Discrete Rib}

SanjayKumar, VijayMittal, N. S. Thakur, Anoop Gautum[11] carried out this experimental study for enhancement of heat transfer coefficient of a solar air heater having roughened air duct provided with artificial roughness in the form $60^{\circ}$ inclined discrete rib. Increment in friction factor by provided with such artificial roughness element has also been studied. The effect of system parameters such as relative roughness height (e/D)0.0249,0.0374\&0.0498, relative roughness pitch $(\mathrm{P} / \mathrm{e}) 8,12 \& 16$ and relative gap position $(\mathrm{d} / \mathrm{W}) 0.15,0.25 \& 0.35$ have been studied on Nusselt number $(\mathrm{Nu})$ and friction factor (f) with relative gap width (g/e) 1 and Reynolds number ( $R e$ ) varied from 4105 to 20526.

Based on experimental result it was concluded that as compared to smooth surface the roughened surface can yield a maximum of about 2.75 fold 3.72 fold increase in nusselt number and friction factor respectively in the range of parameter investigated. The maximum heat transfer enhancement occurs for relative roughness pitch of 12 , relative gap position of 0.35 and relative roughness height of 0.0498 .

\subsubsection{Continuous M Shaped Ribs Turbulators}

Sachin Chaudhary,Varun,Manish Kumar Chauhan[12] concern this experiment with enhancement of heat transfer coefficient using artificial roughened absorber plate on solar air heater. In this study M shape geometry has been studied which is having different orientation. The effect of roughness parameters relative roughness height $(\mathrm{e} / \mathrm{D})$, relative roughness $(\mathrm{P} / \mathrm{e})$ and angle of attack $(\alpha)$ on Nusselt number and friction factor have been seen. The range of Reynolds number $3000-22000$, e/D, P/e and $\alpha$ are 0.037 $0.0776,12.5-75$ and $30-60^{\circ}$ respectively.

After carrying out the detailed experimental investigation, it was studied that the heat transfer and friction factor characteristics of solar air heater duct which is having $\mathrm{M}$ shape artificial roughness on absorber plate. It was reported that Nusselt number is increasing monotonously with the increase in Reynolds number. On the other hand, friction factor also increased which leads to higher pumping power. It is necessary to obtained optimum parameters for artificial roughness $\mathrm{M}$ shape geometry. It has been observed that maximum heat transfer occurred at $0.07769(\mathrm{e} / \mathrm{D}), 25(\mathrm{P} / \mathrm{e})$ and $60^{\circ}$ while maximum friction factor occurs at 0.07769 (e/ D), $25(\mathrm{P} / \mathrm{e})$ and $45^{\circ}$. A maximum heat transfer enhancement due to presence of artificial roughness has been found about 1.7-1.8 times as compared to smooth plate.

\subsubsection{W-Shaped Artificial Roughness}

Lanjewar, Bhagoria and Sarviya[13] carried out this experiment to study heat transfer, friction characteristics and thermo hydraulic performance of roughened absorber plate in solar air heater by using $\mathrm{W}$-shape rib roughness, the roughened wall being heated while the remaining three walls insulated. The roughened wall has relative roughness height $(\mathrm{e} / \mathrm{Dh}) 0.018$, relative roughness pitch $(\mathrm{p} / \mathrm{e}) 10$, rib height $0.8 \mathrm{~mm}$, angle of attack in the range of $30^{\circ}-60^{\circ}$ and duct aspect ratio $(\mathrm{W} / \mathrm{H}) 8$. The air flow rate corresponds to Reynolds number between 2300-14000.

It was reported that the enhancement in Nusselt number over the smooth duct was $32-92 \%, 31-81 \%$ and $9-56 \%$ for $60^{\circ}, 45^{\circ}$ and $30^{\circ}$ respectively. Friction factor ratios for these arrangements were $1.39-1.57,1.32-1.43$ and $1.17-1.27$ respectively. Thermo hydraulic performance parameter improved with increasing the angle of attack of flow and best performance occurs with an angle of attack of $60^{\circ}$. Friction factor results were compared with the correlation for a smooth rectangular duct given by modified blasius equation $\mathrm{fs}=0.085 \mathrm{Re}-0.25$.

\section{Correlations Developed for Heat Transfer and Friction Factor for Different Roughness Geometries}


Table 4. Correlations developed for heat transfer and friction factor for different roughness geometries

\begin{tabular}{|c|c|c|c|}
\hline Investigators & Types of roughness & Parameters & Correlations \\
\hline $\begin{array}{l}\text { Momin,Saini,Solanki( } \\
\text { 2001) }\end{array}$ & V-Shaped rib roughness & $\begin{array}{l}\operatorname{Re} \quad-2500 \quad-18000 \\
(\mathrm{e} / \mathrm{Dh})=0.02-0.034, \quad \alpha \\
=30-90^{\circ}, \text { pitch }-10\end{array}$ & $\begin{array}{l}\text { Nur }=\quad 0.067 \times(\mathrm{Re})^{0.888} \times(\mathrm{e} / \mathrm{Dh})^{0.424} \\
\left.0.782 \times\left(\ln \alpha / 60^{\circ}\right)^{2}\right] \\
\mathrm{Fr}=6.266 \times(\mathrm{Re})^{-0.425} \times(\mathrm{e} / \mathrm{Dh})^{0.565} \\
\times\left(\alpha / 60^{\circ}\right)^{-0.093} \times \exp \left[-0.719 \times\left(\ln \alpha / 60^{\circ}\right)^{2}\right]\end{array}$ \\
\hline $\begin{array}{l}\text { Karwa,Solanki,Saini(2 } \\
000)\end{array}$ & Integral chamfered rib & $\begin{array}{l}\text { Pitch }-4.58-7.09 \text {, duct } \\
\text { depths } 21.8,21.5,16 \\
\text { mm,Re }-3750-16350\end{array}$ & $\begin{array}{l}\text { For } 7 \leq \mathrm{e}^{+}<20 \\
\mathrm{R}=1.66 \mathrm{e}^{-0.0078 \varphi}(\mathrm{W} / \mathrm{H})^{-0.4}(\mathrm{p} / \mathrm{e})^{2.695} \exp \left[-0.762\{\ln (\mathrm{p} / \mathrm{e})\}^{2}\right]\left(\mathrm{e}^{+}\right)^{-0.075} \\
\text { When } / \mathrm{H}>7.75 \text { use } \mathrm{W} / \mathrm{H}=7.75 \\
\mathrm{~g}=103.77 \mathrm{e}^{-0.006 \varphi}(\mathrm{W} / \mathrm{H})^{0.5}(\mathrm{p} / \mathrm{e})^{-2.56} \exp \\
{\left[0.7343\{\ln (\mathrm{p} / \mathrm{e})\}^{2}\right]\left(\mathrm{e}^{+}\right)^{-0.31}} \\
\text { WhenW/H>10 use W/H=10 } \\
\text { For } 20 \leq \mathrm{e}^{+} \leq 60 \\
\mathrm{R}=1.325 \mathrm{e}^{-0.0078 \varphi}(\mathrm{W} / \mathrm{H})^{-0.4}(\mathrm{p} / \mathrm{e})^{2.695} \exp \left[-0.762\{\ln (\mathrm{p} / \mathrm{e})\}^{2}\right] \\
\text { WhenW/H>7.75 use W/H=7.75 } \\
\mathrm{g}=32.26 \mathrm{e}^{-0.006 \varphi}(\mathrm{W} / \mathrm{H})^{0.5}(\mathrm{p} / \mathrm{e})^{-2.56} \exp \\
{\left[0.7343\{\ln (\mathrm{p} / \mathrm{e})\}^{2}\right]\left(\mathrm{e}^{+}\right)^{0.08}}\end{array}$ \\
\hline $\begin{array}{l}\text { Bhagoria,Saini,Solank } \\
\text { i(2001) }\end{array}$ & Transverse wedge shape & $\begin{array}{l}\text { Re }-3000-18000, \\
\text { roughness height } \\
0.075 \quad-0.033 \text { rib } \\
\text { wedge angle }-8, \quad 10 \\
12,15\end{array}$ & $\begin{array}{l}\text { Nur }=1.89 \times 10^{-4}(\mathrm{Re})^{1.21}(\mathrm{e} / \mathrm{Dh})^{0.426}(\mathrm{p} / \mathrm{e})^{2.94} \\
{\left[\exp \left\{-0.71(\ln (\mathrm{p} / \mathrm{e}))^{2}\right\}\right](\varphi / 10)^{-0.018}} \\
{\left[\exp \left\{-1.50(\ln (\varphi / 10))^{2}\right\}\right]} \\
\mathrm{fr}=12.44(\mathrm{Re})^{-0.18}(\mathrm{e} / \mathrm{Dh})^{0.99}(\mathrm{p} / \mathrm{e})^{-0.52} \\
(\varphi / 10)^{0.49}\end{array}$ \\
\hline $\begin{array}{l}\text { Jaruker,Saini,Gandhi( } 2 \\
005)\end{array}$ & Rib-Grooved & $\begin{array}{l}\text { Re-3000-12000,Pitch- } \\
4.5-10, \mathrm{~g} / \mathrm{p}-0.3-0.7\end{array}$ & $\begin{array}{l}\mathrm{Nu}=0.002062 \operatorname{Re}^{0.936-}(\mathrm{e} / \mathrm{D})^{0.349}(\mathrm{p} / \mathrm{e})^{3.318} \\
\times \exp \left[-0.868\{\ln (\mathrm{p} / \mathrm{e})\}^{2}\right](\mathrm{g} / \mathrm{p})^{1.108} \\
\times \exp \left[2.486\{\ln (\mathrm{g} / \mathrm{p})\}^{2}+1.406\{\ln (\mathrm{g} / \mathrm{p})\}^{3}\right] \\
\mathrm{f}=0.001227(\operatorname{Re})^{-0.199}(\mathrm{e} / \mathrm{D})^{0.585}(\mathrm{p} / \mathrm{e})^{7.19} \\
(\mathrm{~g} / \mathrm{p})^{0.645} \times \exp \left(-1.854\{\ln (\mathrm{p} / \mathrm{e})\}^{2}\right) \\
\times \exp \left(1.513\{\ln (\mathrm{g} / \mathrm{p})\}^{2}+0.8662\{\ln (\mathrm{g} / \mathrm{p})\}^{3}\right)\end{array}$ \\
\hline $\begin{array}{l}\text { Varun,Saini, } \\
\text { Singal(2007) }\end{array}$ & $\begin{array}{l}\text { Combination of inclined \& } \\
\text { transverse ribs }\end{array}$ & $\begin{array}{l}\text { Re-2000-14000,Pitch- } \\
5-13 \mathrm{~mm}, \mathrm{~W} / \mathrm{H}-10\end{array}$ & $\begin{array}{l}\mathrm{Nu} / \mathrm{Re}^{1.213}=0.0006 \times(\mathrm{p} / \mathrm{e})^{0.0104} \text { and } \\
\mathrm{Nu}=0.0006 \times \mathrm{Re}^{1.213} \times(\mathrm{p} / \mathrm{e})^{0.0104} \\
\mathrm{f} / \mathrm{Re}^{-0.3685}=1.0858 \times(\mathrm{p} / \mathrm{e})^{0.0114} \text { and } \\
\mathrm{f}=1.0858 \times \mathrm{Re}^{-0.3685} \times(\mathrm{p} / \mathrm{e})^{0.0104}\end{array}$ \\
\hline $\begin{array}{l}\text { Karmare\&Tikekar } \\
(2008)\end{array}$ & Metal rib grit roughness & $\begin{array}{l}\text { Re-3600-17000,Pitch- } \\
15-17.5 \text {, e/Dh- 0.035- } \\
0.044\end{array}$ & $\begin{array}{l}\mathrm{f}=15.55 \times(\mathrm{Re})^{-0.26} \times(\mathrm{e} / \mathrm{Dh})^{0.91} \times(1 / \mathrm{s})^{-0.27} \\
\times(\mathrm{p} / \mathrm{e})^{-0.51} \text { for } 3600<\mathrm{Re}<17000 \\
\mathrm{Nu}=2.4 \times 0^{-3} \times(\mathrm{Re})^{1.3} \times(\mathrm{e} / \mathrm{Dh})^{0.42} \times(1 / \mathrm{s})^{-0.146} \\
\times(\mathrm{p} / \mathrm{e})^{-0.27} \text { for } 3600<\mathrm{Re}<17000\end{array}$ \\
\hline Saini \& Saini (2008) & Arc shaped wire & $\begin{array}{l}\text { Re-2000- } \\
\text { 17000,Pitch-10, } \alpha / 90- \\
0.3333-0.6666, \text { W/H- } \\
12\end{array}$ & $\begin{array}{l}\mathrm{Nu}=0.001047 \operatorname{Re} 1.3186(\mathrm{e} / \mathrm{d}) 0.3772 \\
(\alpha / 90)-0.1198 \\
\mathrm{f}=0.14408 \operatorname{Re}-0.17103(\mathrm{e} / \mathrm{d}) 0.1765 \\
(\alpha / 90) 0.1185\end{array}$ \\
\hline $\begin{array}{l}\text { Thakur Sanjay } \\
\text { Kumar et al. (2011) }\end{array}$ & $\begin{array}{l}\text { Continuous } \mathrm{M} \text { shaped ribs } \\
\text { turbulators }\end{array}$ & $\begin{array}{l}\text { Re-3000-22000, } \\
\text { Pitch-12.5-75, } \alpha-30- \\
60^{\circ}, \quad \text { e/D-0.037- } \\
0.0776\end{array}$ & $\begin{array}{l}\mathrm{Nu}=3 \times 10-5(\mathrm{Re}) 0.947(\mathrm{e} / \mathrm{D}) 0.290(\mathrm{p} / \mathrm{e}) 5.885 \\
(\mathrm{~d} / \mathrm{w}) 0.115 \times \exp [-1.237(\ln (\mathrm{p} / \mathrm{e})) 2] \\
\mathrm{f}=0.014 \mathrm{Re}-0.23(\mathrm{e} / \mathrm{D}) 0.804(\mathrm{~d} / \mathrm{w}) 0.097 \\
0.944(\ln (\mathrm{p} / \mathrm{e})) 2)\end{array}$ \\
\hline
\end{tabular}

\section{Conclusion}

- This Paper reviews the investigation carried out by various investigators in order to enhance the heat transfer by use of artificial roughness.

- Use of artificially roughened surfaces with different type of roughness geometries of different shapes, sizes and orientation is found to be the most effective technique to enhance the heat transfer rate with little penalty of friction.

- Roughness in the form of ribs and wire matrix were mainly suggested by different investigators to achieve better thermal performance. Among all, rib roughness was found the best performer as far as thermal performance is concerned.

- Correlations developed for heat transfer and friction factor for solar air heater ducts having artificial roughness of different geometries for different investigators are also shown in tabular form. These correlations can be used to predict the thermal efficiency, effective efficiency and then hydraulic performance of artificial roughened solar air heater ducts.

\section{Scope for Future Work}

- Broken inclined rib roughness performed excessively well as compared to continuous inclined rib roughness and therefore the performance of multi $\mathrm{V}$ rib roughness shall be improved by introducing gap at suitable location.

- V ribs arranged in transverse direction which were tested recently showed outstanding performance and in future these $\mathrm{V}$ rib arrays could be arranged inclined to the 
direction of flow and subsequently arrays arranged in $\mathrm{V}$ type fashion could be tested in the quest of higher heat transfer rates.

- It was observed that wedge shape rib roughness performed better than other rib shapes as far as heat transfer enhancement rate is concerned and therefore wedge shape ribs combined with grooves could be the better combination in order to get better enhancement rates in heat transfer.

- Ribs of different shapes like chamfered, wedge are to be used in making inclined and $\mathrm{V}$ type roughness geometries to achieve higher heat transfer enhancements.

\section{Nomenclature}

$\mathrm{D}$ - equivalent diameter of the air passage (m)

$\mathrm{d} / \mathrm{w}$ - relative gap position

e/D - relative roughness height

$\mathrm{fr}$ - friction factor of roughened duct

fs - friction factor of smooth duct

$\mathrm{g}$ - heat transfer function ( $\mathrm{g}$-function)

$\mathrm{g} / \mathrm{e}$ - relative gap width

$\mathrm{g} / \mathrm{p}$ - groove position to pitch ratio

$1 / \mathrm{s}$ - relative length of metal grit

$\mathrm{L} / \mathrm{e}$ - relative long way length

$\mathrm{S} / \mathrm{e}$ - relative short way length

$\mathrm{Nu}$ - Average Nusselt number

Nur - Nusselt number for roughened duct

Nus - Nusselt number for smooth duct

$\mathrm{P}$ - roughness pitch (m)

$\mathrm{p} / \mathrm{e}$ - relative roughness pitch

$\mathrm{R}$ - roughness function

Re - Reynolds number

Greek Symbols -

$\alpha$ - angle of attack

$\alpha / 90$ - relative angle of attack

$\varphi$ - wedge angle

\section{References}

[1] Momin A-M.E., Saini J.S., Solanki S.C. Heat transfer and friction in solar air heater duct with Vshaped rib roughness on absorber plate. International J. of Heat and Mass Transfer. 2001, 45(16), 3383-3396.

[2] Karwa R., Solanki S.C., and Saini J.S. Thermo-hydraulic performance of solar air heaters having integral chamfered rib-groove roughness on absorber plates. Energy. 2000, 26,161-176.

[3] Bhagoria J.L., Saini J.S. and Solanki S.C.,Heat transfer coefficient and friction factor correlations for rectangular solar air heater duct having transverse wedge shaped rib roughness on the absorber plate, Renew.Ene., 25(3), 341-
$369,(2001)$

[4] Sahu M.M. and Bhagoria J.L., Augmentation of heat transfer coefficient by using $90^{\circ}$ broken transverse ribs on absorber plate of solar air heater, Renew. Ene., 30 (13) 2057-2073,(2005)

[5] Jaurker A.R., Saini J.S., and Gandhi B.K. Heat transfer coefficient and friction characteristics ofrectangular solar air heater duct using rib-grooved artificial roughness. Solar Energy. 2005, 80(8),895-907.

[6] Varun, Saini R.P., Singal S.K. Investigation of thermal performance of solar air heater havingroughness elements as a combination of inclined and transverse ribs on absorber Plate. RenewableEnergy. 2007, 33(6), 1398-1405.

[7] Aharwal K.R, Gandhi B.K, Saini J.S. Heat transfer and friction characteristics of solar air heater duct having gap in integral inclined continuous ribs on absorber plate. International Journal of Heat andMass Transfer. Renewable Energy 33 (2007) 585-596

[8] Karmare S.V., Tikekar A.N. Heat transfer and friction factor correlation for artificially roughened duct with metal grit ribs. International Journal of Heat and Mass Transfer. S.V. Karmare, A.N. Tikekar / Solar Energy 83 (2008) 6-13.

[9] Layek A., Saini J.S., and Solanki S.C. Heat transfer and friction characteristics for artificially roughened ducts with compound turbulators. International Journal of Heat and Mass Transfer. A. Layek et al. / Renewable Energy 34 (2008) 1292-1298

[10] Saini S.K., Saini R.P., "Development of Correlations for Nusselt Number and Friction Factor for Solar Air Heater with Roughened Duct Having Arc Shaped Wire as Artificial Roughness", Solar Energy, 2008, vol.82, pp.1118-1130

[11] Kumar Thakur Sanjay,Thakur N.S, Kumar Anoop, Mittal Vijay, Heat Transfer and Friction Factor Correlations for Rectangular Solar Air Heater Duct Having $60^{\circ}$ Inclined Continuous Discrete Rib Arrangement, British Journal of Applied Science \& Technology, 1(3):67-93, 2011

[12] Kumar Thakur Sanjay,Thakur N.S, Kumar Anoop, Mittal Vijay, "Use of Artificial Roughness to Enhance Heat Transfer in Solar Air Heaters - A Review”, Energy, 2010, vol.21, pp.35-51.

[13] Choudhary sachin, Varun, Chouhan Kumar Manish Heat transfer and friction factor characteristics using continuous $M$ shape ribs turbulators International Journal of Energy and Environment (IJEE), Volume 3, Issue 1, 2012, pp.33-48

[14] Lanjewar.A.M,Bhagoria.J.L,Sarviya.R.M Thermohydaulic Performance Of Solar Air Collector Using W-Shaped Artificial Roughness Journal of Environmental Research And Development Vol. 6 No. 3A, Jan-March 2012

[15] A.K.Patil, J.S.Saini, K.Kumar A Comprehensive Review on Roughness Geometries and Investigation Techniques Used in Artificially Roughened Solar Air Heaters International Journal of Renewable Energy Resarch, Vol.2, No.1, 2012 